\title{
PENGARUH MEDIA BOOKLET TERHADAP PENINGKATAN PENGETAHUAN, SIKAP DAN PERILAKU PASIEN DIABETES MELLITUS \\ DALAM PENCEGAHAN KELAINAN PERIODONTAL DI PUSKESMAS II DENPASAR UTARA TAHUN 2018
}

\author{
Anak Agung Gede Agung ${ }^{1}$, I Nyoman Wirata ${ }^{2}$, Ni Wayan Arini ${ }^{3}$ \\ Dosen Jurusan Kesehatan Gigi Poltekkes Kemenkes Denpasar
}

\begin{abstract}
Periodontal disorders is one of the risks that can occur at patients with Diabetes Mellitus. The ignorance of patients for prevention and checking their teeth and mouth that caused periodontitis and result in early tooth lossed. The one solution that can be done for Diabetes Mellitus patients in preventing of periodontal disorders is to right brush their teeth regularly. The aim of the study was to analyze the influence of booklet to increase of knowledge, attitude, and behaviour of Diabetes Mellitus patients in prevention of periodontal diseases in prevention of periodontal diseases at Puskesmas II Denpasar Utara in 2018. The type of this study is action research that was in dental health education form to improve the knowledge and behaviour to maintain the healthy teeth to total population that amount to 100 patients with Diabetes Mellitus in Puskesmas II Denpasar Utara. The results of this study were based on Paired Sample Test and Willcoxon showed that there is a significant effect on using the booklet to increase of knowledge, attitudes, and behavior of tooth brushing that each $\mathrm{p}=0.00$ $(p<0.05)$. Conclusion The use of booklet media has an effect on increasing knowledge, attitudes and behavior of patients with diabetes mellitus in an effort to prevent periodontal disorders.
\end{abstract}

Keywords : booklets, tooth brushing behaviour, periodontal diseases, Diabetes Mellitus

Pendahuluan

Menurut survey yang dilakukan oleh organisasi kesehatan dunia (WHO), secara global penderita diabetes mellitus terus meningkat dari tahun ketahun, Jumlah penderita diabetes mellitus di dunia pada tahun 2000 tercatat sebesar 175,4 juta orang, dan diperkirakan jumlah tersebut akan mengalami peningkatan pada tahun 2030 menjadi 366 juta orang (1). Sedangkan untuk di Indonesia jumlah penderita diabetes mellitus pada tahun 2000 tercatat sebesar 8,4 juta orang, jumlah tersebut menempati urutan keempat terbesar di dunia setelah India, Cina dan Amerika Serikat (2). Menurut data Dinas Kesehatan Propinsi Bali untuk tahun 2016 kasus diabetes mellitus untuk Propinsi Bali tercatat sebesar $8.815 \quad(6,863 \%)$. Sedangkan kasus diabetes mellitus untuk kota Denpasar pada tahun 2016 tercatat sebesar 1.528 (9,696\%). Dalam skala prioritas penelitian Link and Mach Politeknik Kesehatan Denpasar tahun 2016 - 2020, memprioritaskan salah satu program prioritas penelitian ditujukan pada 
kelompok penderita penyakit tidak menular, salah satunya adalah penyakit diabetes mellitus. Diabetes mellitus dapat memberikan komplikasi ke semua organ tubuh dan menimbulkan berbagai macam keluhan dengan gejala yang bervariasi. Bila hal ini dibiarkan bisa berdampak komplikasi acut maupun kronis, salah satunya yang sering dijumpai pada rongga mulut adalah penyakit periodontal yang bisa menyebabkan gigi goyang dan bahkan kehilangan gigi (3). Diabetes mellitus dengan kelainan penyakit periodontal merupakan masalah penting yang harus segera ditangani, pendidikan kesehatan yang dilakukan petugas kesehatan yang merupakan pilar pertama dari empat pilar penatalaksanaan diabetes mellitus, dan kurangnya pengetahuan dan ketidak tahuan pasien diabetes mellitus dalam melakukan pemeriksaan gigi dan mulut mengakibatkan resiko penyakit periodontal semakin meningkat dan kehilangan gigi menjadi lebih dini (4). Dalam artikel edukasi diabetes (2016), menyatakan bahwa solusi yang dapat dilakukan bagi penderita diabetes mellitus dalam mengatasi penyakit jaringan periodontal adalah melalui menyikat gigi secara teratur. Sedangkan menurut Berliana Sari, dkk (2017), bahwa pencegahan dapat dilakukan dengan teratur menyikat gigi yang tepat, flossing, dan kunjungan berkala ke dokter gigi ${ }^{(3)}$. Berdasarkan rekapitulasi laporan data kunjungan yang diperoleh di Puskesmas II Denpasar Utara juga menunjukkan adanya peningkatan kasus diabetes mellitus setiap tahunnya yakni pada tahun 2014 jumlah kunjungan tercatat sebesar 74 orang, dan pada tahun 2015 mengalami peningkatan menjadi 186 orang, sedangkan pada tahun 2016 jumlah kunjungan sebesar 198 orang (Data PTM Puskesmas II Denpasar Utara, 2016). Peningkatan kasus diabetes mellitus ini juga diiringi dengan peningkatan kasus penyakit periodontal di Puskesmas II Denpasar Utara

\section{Tujuan}

Tujuan Penelitian ini adalah untuk menganalisis Pengaruh Media Booklet Terhadap Peningkatan Pengetahuan, Sikap Dan Perilaku Pasien Diabetes Mellitus Dalam Pencegahan Kelainan Periodontal di Puskesmas II Denpasar Utara Tahun 2018.

\section{Metode}

Jenis penelitian dan desain penelitian ini adalah pre eksprimen atau penelitian tindakan (5), dalam hal ini adalah pendidikan kesehatan gigi untuk meningkatkan pengetahuan dan keterampilan memelihara kesehatan gigi. Penelitian ini dilakukan diwilayah kerja Puskesmas II Denpasar Utara dari bulan Maret-Oktober 2018. Populasi dalam 
penelitian ini adalah semua pasien diabetes mellitus yang berkunjung ke Puskesmas II Denpasar Utara, data awal berjumlah 100 orang.Sampel penelitian adalah total populasi, yaitu seluruh pasien diabetes mellitus yang berkunjung ke Puskesmas II Denpasar Utara pada bulan Maret-Oktober 2018. Sampel diambil secara Acidental Random Sampling. Sampel kasus dan kontrol ditentukan dengan cara acak sederhana. Besar sampel adalah sebanyak 100 orang. Jenis data yang dikumpulkan adalah data primer dan data sekunder, data primer antara lain tingkat pengetahuan dan sikap, perilaku. Data dikumpulkan dengan cara test dan wawancara serta observasi yakni: Jawaban yang diberikan oleh pasien diabetes militus terhadap pertanyaan dari test sebelum dan sesudah diberikan pendidikan menyikat gigi . Respons yang diberikan oleh pasien terhadap pertanyaan dari kuesioner melalui wawancara sebelum dan sesudah diberikan pendidikan menyikat gigi. Unjuk kerja cara/teknik menyikat gigi dengan benar yang dilakukan oleh pasien sebelum dan 21 hari sesudah diberikan pendidikan menyikat. Data dianalisis secara statistik dengan uji univariat menghitung median dan persentase, dan analisis bevariat untuk uji komparabilitas dengan Willcoxon Match Pairs Test dan untuk menganalisis perbedaan pengaruh perlakuan diuji dengan Mann withney $U$ Test ${ }^{(6)}$.

Hasil

1. Hasil Penelitian terhadap Tingkat pengetahuan responden sebelum diberikan penyuluhan dan pembagian booklet.

Tingkat pengetahuan responden sebelum dan setelah diberikan penyuluhan disajikan pada tabel 5 berikut:

Tabel 5. Nilai Median Pengetahuan Responden Sebelum dan Setelah Diberikan Penyuluhan dengan Ceramah dan Media Booklet

\begin{tabular}{|c|c|c|}
\hline No & $\begin{array}{l}\text { Nilai median } \\
\text { pengetahun } \\
\text { responden } \\
\text { kelompok yang } \\
\text { diberikan ceramah }\end{array}$ & $\begin{array}{l}\text { Nilai median } \\
\text { pengetahuan } \\
\text { responden } \\
\text { kelompok media } \\
\text { booklet }\end{array}$ \\
\hline 1 & Sebelum Setelah & Sebelum Setelah \\
\hline 2 & 5 & 5 \\
\hline
\end{tabular}

Tabel 5 menunjukkan bahwa nilai tengah atau median pengetahuan responden sebelum diberikan penyuluhan dengan ceramah adalah 5 dan setelah diberikan penyuluhan dengan ceramah nilai median pengetahuan responden menjadi 7 , jadi meningkat 2 . Nilai median pengetahuan responden sebelum diberikan booklet adalah 5 dan setelah diberikan booklet meningkat menjadi 9 .

Hasil penelitian terhadap tingkat pengetahuan responden sebelum dan setelah diberikan penyuluhan ceramah dan booklet seperti pada tabel 6 berikut: 
Tabel 6. Tingkat Pengetahuan Responden Sebelum dan Setelah Diberikan Penyuluhan dengan Ceramah dan Media Booklet

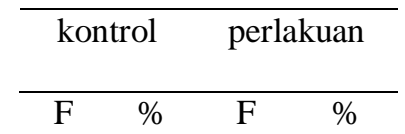

\begin{tabular}{llllll}
\hline Pengetahuan & Tinggi & 8 & 16 & 9 & 18 \\
$\begin{array}{l}\text { sebelum } \\
\text { perlakuan }\end{array}$ & Sedang & 30 & 60 & 29 & 58 \\
\cline { 2 - 6 } & Rendah & 12 & 24 & 12 & 24 \\
\hline $\begin{array}{l}\text { Pengetahuan } \\
\text { setelah } \\
\text { perlakuan }\end{array}$ & Tinggi & 19 & 38 & 39 & 78 \\
\cline { 2 - 6 } & Sedang & 12 & 24 & 9 & 18 \\
\cline { 2 - 6 } & Rendah & 19 & 38 & 2 & 4
\end{tabular}

Tabel 6 menujukkan bahwa responden yang berpengetahun tinggi sebelum diberikan booklet hanya 9 responden dan setelah diberikan booklet ada sebanyak 39 responden yang berpengetahuan tingi.

2. Hasil penelitian terhadap sikap responden sebelum dan setelah diberikan penyuluhan dan media booklet

$$
\text { Perubahan sikap responden }
$$
sebelum dan setelah diberikan penyuluhan dan booklet seperti pada 7 berikut:
Tabel 7. Sikap Responden Sebelum dan Setelah Diberikan Penyuluhan dengan Ceramah dan Media Booklet

\begin{tabular}{|c|c|c|c|c|}
\hline \multirow{2}{*}{$\begin{array}{l}\text { No } \\
\\
\\
1\end{array}$} & \multicolumn{2}{|c|}{$\begin{array}{l}\text { Sikap yang benar } \\
\text { pada kelompok yang } \\
\text { diberikan ceramah }\end{array}$} & \multicolumn{2}{|c|}{$\begin{array}{l}\text { Sikap yang benar } \\
\text { pada kelompok } \\
\text { responden yang } \\
\text { diberikan media } \\
\text { booklet }\end{array}$} \\
\hline & Sebelum & Setelah & sebelum & setelah \\
\hline 2 & $7(14 \%)$ & $\begin{array}{l}17 \\
(34 \%)\end{array}$ & $9(18 \%)$ & $29(58 \%)$ \\
\hline
\end{tabular}

Tabel 7 menunjukkan bahwa hasil penelitian terhadap perubahan sikap responden pada kelompok yang diberikan media booklet yaitu sebelum diberikan media booklet hanya 9 responden atau $18 \%$ yang bersikap benar dalam mencegah kelaianan periodontal dan setelah diberikan media booklet sebanyak 29 responden atau $58 \%$ responden yang mempunyai sikap benar dalam mencegah kelainan penyakit periodontal. Hasil penelitian terhadap sikap pada kelompok yang diberikan ceramah yakni sebelum diberikan ceramah ada sebanyak 7 rersponden atau $14 \%$ responden yang 
bersikap benar dalam mencegah kelaianan periodontalnya dan setelah diberikan penyuluhan dengan ceramah ada sebanyak 17 responden $34 \%$ responden yang bersikap benar dalam mencegah kelainan periodontal.

3. Hasil Penelitian terhadap Perubahan perilaku sebelum dan setelah diberikan penyuluhan dengan metode ceramah dan media booklet.

$$
\text { Hasil penelitian terhadap }
$$
perubahan perilaku sebelum dan setelah diberikan penyuluhan dengan metode ceramah dan media booklet, seperti pada tabel 8 berikut:

Tabel 8. Nilai Median Perilaku Responden Sebelum dan Setelah Diberikan Penyuluhan dengan Ceramah dan Media Booklet

\begin{tabular}{lllll}
\hline No & $\begin{array}{l}\text { Nilai median } \\
\text { perilaku responden } \\
\text { kelompok yang } \\
\text { diberikan ceramah }\end{array}$ & $\begin{array}{l}\text { Nilai median } \\
\text { perilaku responden } \\
\text { kelompok media } \\
\text { booklet }\end{array}$ \\
\hline & & & & \\
\hline 1 & Sebelum & Setelah & Sebelum & Setelah \\
2 & 9 & 14 & 7 & 16 \\
\hline
\end{tabular}

Tabel 8 menunjukkan bahwa nilai median pada kelompok perlakuan meningkat lebih tinggi daripada nilai median pada kelompok kontrol.
Hasil penelitian terhadap perubahan perilaku sebelum dan setelah diberikan penyuluhan dengan metode ceramah dan media booklet berdasarkan kategori, seperti pada tabel 9 berikut:

Tabel 9. Perilaku Responden Sebelum dan Setelah Diberikan Penyuluhan dengan Ceramah dan Media Booklet

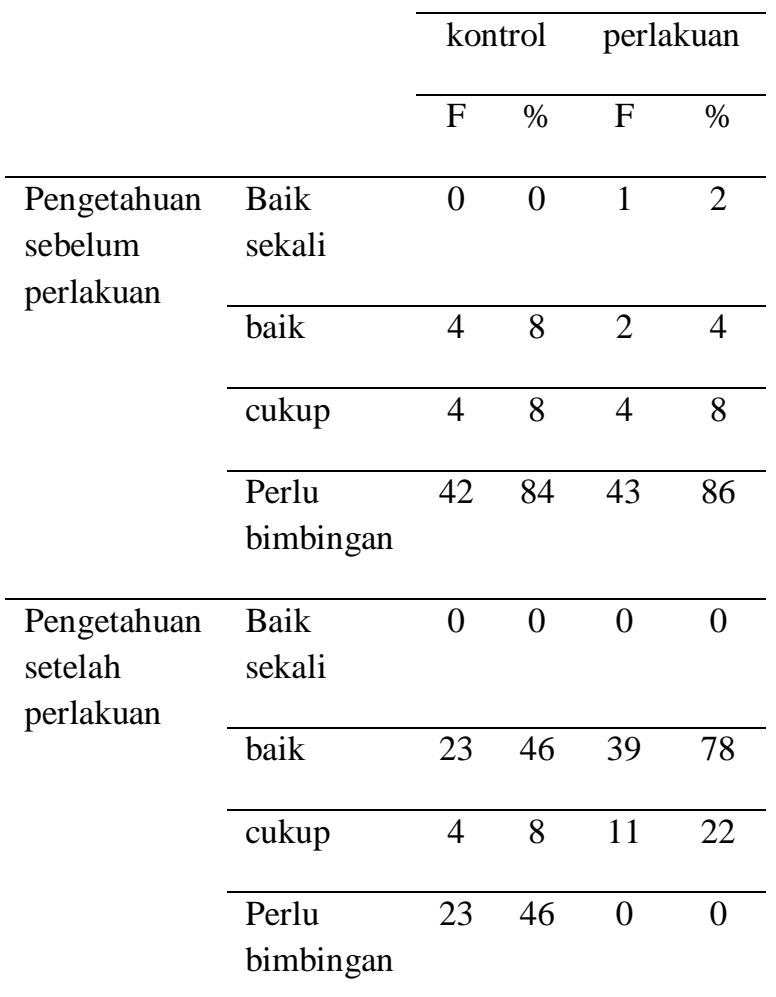

Tabel 9 menunjukkan bahwa sebelum diberikan booklet ada sebanyak 42 orang atau $84 \%$ responden kategori perlu bimbingan. Setelah diberikan booklet tidak ada yang kategori perlu bimbingan. Pada kelompok responden yang hanya 
diberikan ceramah saja ada sebanyak 23 responden atau $46 \%$ yang masih kategori perlu bimbingan.

\section{Hasil Analisis dengan Uji Statistik}

a. Hasil uji Pemberian media booklet terhadap peningkatan pengetahuan tentang cara menyikat gigi dalam upaya pencegahan kelainan periodontal.

Hasil uji pengaruh media bokklet terhadap peningkatan pengetahun tentang cara menyikat gigi dalam upaya pencegahan kelaianan eriodontal pada pasien diabetes mellitus di Puskesmas II Denpasar Utara tahun 2018 seperti pada tabel 10 berikut.

Tabel 10 Hasil Uji Pengaruh Media Booklet terhadap Peningkatan Pengetahun tentang Cara Menikat Gigi dalam Upaya Pencegahan Kelainan Periodontal pada Pasien Diabetes Mellitus di Puskesmas II Denpasar Utara tahun 2018

\begin{tabular}{cccccc}
\hline Perilaku & $\mathrm{N}$ & $\begin{array}{l}\text { Mean } \\
\text { Rank }\end{array}$ & $\mathrm{Z} \quad \mathrm{P}$ & & \\
\hline Pre Test & 50 & 5,50 & $-6,053$ & 0,000 \\
& & & & \\
Post Test & & & 24,50 & &
\end{tabular}

Hasil penelitian dengan menggunakan uji ststistik terhadap pengetahuan tentang cara menyikat gigi dalam upaya pencegahan kelainan periodontal responden sebelum dan setelah diberikan booklet diperoleh nilai $\mathrm{p}=0,00$ nilai $\mathrm{Z}=(-6.053)$. artinya ada pengaruh yang bermakna penggunaan media booklet terhadap peningkatan pengetahuan responden.

b. Hasil Uji Pengaruh Penyuluhan dengan Metode Ceramah terhadap Peingkatan Pengetahuan Responden tentang Menyikat Gigi dalam Upaya Pencegahan Kelainan Periodontal

Hasil penelitian terhadap pengaruh penyuluhan ceramah dengan peningkatan pengetahuan tentang cara menyikat gigi dalam upaya pencegahan kelainan periodontal pada responden seperti pada tabel 11 berikut:

Tabel 11 Hasil Uji Pengaruh Metode Ceramah terhadap Peningkatan Pengetahun tentang Cara Menyikat Gigi dalam Upaya Pencegahan Kelainan Periodontal pada Pasien Diabetes Mellitus di Puskesmas II Denpasar Utara tahun 2018

\begin{tabular}{ccccc}
\hline Perilaku & N & Mean Rank & Z & P \\
& & & & \\
\hline Pre Test & 50 & 18,50 & - & 0,000 \\
Post Test & & 23,61 & & \\
& & & &
\end{tabular}

Tabel 9 menunjukkan bahwa nilai $\mathrm{p}=0,00$ dan nilai $\mathrm{Z}=-5,753$. Hasil ini menunjukkan bahwa terdapat pengaruh yang bermakna penyuluhan ceramah terhadap peningkatan pengetahaun tentang cara menyikat gigi dalam upaya 
pencegahan kelainan periodontal pada responden.

Hasil uji terhadap perbedaan pengaruh pemberian penyuluhan dengan metode ceramah dan booklet terhadap peningkatan pengetahuan menyikat gigi dalam pencegahan kelainan periodontal pada pasien diabetes mellitus di Puskesmas II Denpasar Utara tahun 2018 disajikan seperti pada tabel 12 berikut:

Tabel 12. Hasil Uji Perbedaan Pengaruh Metode Ceramah dan booklet terhadap Peningkatan Pengetahuan Menyikat Gigi dalam Upaya Pencegahan Kelainan Periodontal pada Pasien Diabetes Mellitus di Puskesmas II Denpasar Utara tahun 2018

\begin{tabular}{ccccc}
\hline Perilaku & N & Mean Rank & $\mathrm{Z}$ & $\mathrm{P}$ \\
& & & & \\
\hline Ceramah & 50 & 37,61 & - & 0,000 \\
& & & 4,619 &
\end{tabular}

$\begin{array}{lll}\text { Booklet } & 50 & 63,39\end{array}$

Tabel 12 menunjukkan bahwa pengaruh perlakuan dengan booklet menunjukkan lebih besar daripada ceramah, yakni nilai mean rank booklet sebesar 63,39 sedangkan ceramah sebesar 37,61 .

c. Hasil uji pengaruh booklet tehadap perubahan sikap responden dalam mencegah kelaianan periodontal

Hasil uji pemberian booklet terhadap peningkatan sikap pencegahan kelainan periodontal pada pasien diabetes mellitus di Puskesmas II Denpasar Utara tahun 2018 disajikan seperti pada tabel 13 berikut:

Tabel 13 Hasil Uji Pengaruh Media Booklet terhadap Peningkatan Sikap Pencegahan Kelainan Periodontal pada Pasien Diabetes Mellitus di Puskesmas II Denpasar Utara tahun 2018

\begin{tabular}{lcccc}
\hline Perilaku & $\mathrm{N}$ & $\begin{array}{l}\text { Mean } \\
\text { Rank }\end{array}$ & $\mathrm{Z}$ & $\mathrm{P}$ \\
\hline Pre Test & 50 & 12,50 & - & 0,000 \\
Post Test & & 22,46 & 5,558 & \\
& & & & \\
\hline
\end{tabular}

Tabel 13 menunjukkan bahwa diperoleh nilai $\mathrm{p}=0,00(\mathrm{p}<0,05)$ berarti ada pengaruh yang bermakna pemberian media booklet terhadap peningkatan sikap untuk mencegah kelainan periodontal pada pasien diabetes mellitus di Puskesmas II Denpasar Utara

d. Hasil uji pengaruh ceramah tehadap perubahan sikap responden dalam mencegah kelaianan periodontal

Hasil uji pemberian ceramah terhadap peningkatan sikap pencegahan kelainan periodontal pada pasien diabetes mellitus di Puskesmas II Denpasar Utara tahun 2018 disajikan seperti pada tabel 14 berikut:

Tabel 14 Hasil Uji Pengaruh Ceramah terhadap Peningkatan Sikap 
Pencegahan Kelainan

Periodontal pada Pasien

Diabetes Mellitus di Puskesmas

II Denpasar Utara tahun 2018

\begin{tabular}{ccccc}
\hline Perilaku & $\mathrm{N}$ & Mean Rank & $\mathrm{Z}$ & $\mathrm{P}$ \\
& & & & \\
\hline Pre Test & 50 & 10,00 & - & 0,000 \\
& & & 3,854 & \\
Post & & 12,19 & & \\
Test & & & & \\
& & & & \\
\hline
\end{tabular}

Hasil analisis diperoleh nilai $\mathrm{p}=$ $0,00 \quad(\mathrm{p}<0,05)$ berarti ada pengaruh penyuluhan dengan ceramah terhadap peningkatan sikap untuk mencegah kelainan periodontal pada pasien diabetes mellitus di puskesmas II Denpasar Utara tahun 2018.

Hasil uji terhadap perbedaan pengaruh pemberian penyuluhan dengan metode ceramah dan booklet terhadap peningkatan sikap menyikat gigi dalam pencegahan kelainan periodontal pada pasien diabetes mellitus di Puskesmas II Denpasar Utara tahun 2018 disajikan seperti pada tabel 15 berikut:

Tabel 15. Hasil Uji Perbedaan Pengaruh Metode Ceramah dan booklet terhadap Peningkatan Sikap Menyikat Gigi dalam Upaya Pencegahan Kelainan Periodontal pada Pasien Diabetes Mellitus di Puskesmas II Denpasar Utara tahun 2018

\begin{tabular}{ccccc}
\hline Perilaku & N & $\begin{array}{c}\text { Mean } \\
\text { Rank }\end{array}$ & $\mathrm{Z}$ & $\mathrm{P}$ \\
& & & & \\
\hline Ceramah & 50 & 38,45 & $\begin{array}{c}- \\
5,743\end{array}$ & 0,000 \\
& & & & \\
\hline Booklet & 50 & 64,55 & & \\
\hline
\end{tabular}

Tabel 15 menunjukkan bahwa pengaruh perlakuan dengan booklet menunjukkan lebih besar daripada ceramah, yakni nilai mean rank booklet sebesar 64,55 sedangkan ceramah sebesar 38,45 .

e. Hasil uji pengaruh media booklet tehadap perubahan perilaku responden dalam mencegah kelaianan periodontal

Hasil uji pengaruh pengunaan media booklet terhadap peningkatan perilaku menyikat gigi dalam upaya pencegahan kelainan periodontal pada pasien diabetes mellitus di Puskesmas II Denpasar Utara tahun 2018 disajikan seperti pada tabel 16 berikut:

Tabel 16 Hasil Uji Pengaruh Media Booklet terhadap Peningkatan perilaku Menyikat Gigi dalam Upaya Pencegahan Kelainan Periodontal pada Pasien Diabetes Mellitus di Puskesmas II Denpasar Utara tahun 2018

\begin{tabular}{lcccc}
\hline Perilaku & $\mathrm{N}$ & Mean Rank & $\mathrm{Z}$ & $\mathrm{P}$ \\
\hline Pre Test & 50 & 5,50 & - & 0,000 \\
& & & 5,998 & \\
Post & & 25,83 & & \\
Test & & & &
\end{tabular}

Tabel 16 menunjukkan bahwa hasil uji statistik diperoleh nilai $\mathrm{p}=0,00$ $(\mathrm{p}<0,05)$ berarti ada pengaruh yang bermakna pemberian media booklet terhadap peningkatan perilaku menyikat 
gigi dalam upaya pencegahan kelainan periodontal pada pasien diabetes mellitus di puskesmas II Denpasar Utara tahun 2018.

f. Hasil uji analisis pengaruh penyuluhan dengan metode ceramah terhadap perubahan perilaku menyikat gigi dalam upaya pencegahan kelainan periodontal pada pasien diabetes melitus di Puskesmas II Denpasar Utara tahun 2018

Hasil uji pemberian penyuluhan dengan metode ceramah terhadap peningkatan perilaku menyikat gigi dalam pencegahan kelainan periodontal pada pasien diabetes mellitus di Puskesmas II Denpasar Utara tahun 2018 disajikan seperti pada tabel 17 berikut:

Tabel 17. Hasil Uji Pengaruh Metode Ceramah terhadap Peningkatan Perilaku Menyikat Gigi dalam Upaya Pencegahan Kelainan Periodontal pada Pasien Diabetes Mellitus di Puskesmas II Denpasar Utara tahun 2018

\begin{tabular}{ccccc}
\hline Perilaku & $\mathrm{N}$ & Mean Rank & $\mathrm{Z}$ & $\mathrm{P}$ \\
& & & & \\
\hline Pre Test & 50 & 11,83 & - & 0,000 \\
Post Test & & 21,20 & & \\
& & & & \\
\hline
\end{tabular}

Tabel 17 menunjukkan bahwa hasil analisis diperoleh nilai $\mathrm{p}=0,00(\mathrm{p}<0,05)$ berarti ada pengaruh pemberian penyuluhan dengan metode ceramah terhadap peningkatan perilaku menyikat gigi dalam upaya mencegah kelainan periodontal pada pasien diabetes mellitus di Puskesmas II Denpasar Utara tahun 2018.

Hasil uji terhadap perbedaan pengaruh pemberian penyuluhan dengan metode ceramah dan booklet terhadap peningkatan perilaku menyikat gigi dalam pencegahan kelainan periodontal pada pasien diabetes mellitus di Puskesmas II Denpasar Utara tahun 2018 disajikan seperti pada tabel 18 berikut:

Tabel 18. Hasil Uji Perbedaan Pengaruh Metode Ceramah dan booklet terhadap Peningkatan Perilaku Menyikat Gigi dalam Upaya Pencegahan Kelainan Periodontal pada Pasien Diabetes Mellitus di Puskesmas II Denpasar Utara tahun 2018

\begin{tabular}{ccccc}
\hline Perilaku & $\mathrm{N}$ & $\begin{array}{l}\text { Mean } \\
\text { Rank }\end{array}$ & $\mathrm{Z}$ & $\mathrm{P}$ \\
\hline Ceramah & 50 & 41,19 & $-3,454$ & 0,001 \\
\hline Booklet & 50 & 59,81 & & \\
\hline
\end{tabular}

Tabel 18 menunjukkan bahwa pengaruh perlakuan dengan booklet terlihat lebih besar daripada ceramah, terhadap perubahan perilaku menyikat gigi pada pasien diabetes mellitus ini dapat dilihat dari nilai mean rank booklet sebesar 59,81 sedangkan ceramah sebesar 41,19.

\section{Pembahasan}


Penderita Diabetes Mellitus sangat rentan mengalami kelainan periodontal. Perilaku menyikat gigi merupakan salah satu perilaku kesehatan yang sangat penting dan efektif untuk pemeliharaan kesehatan gigi dan mulut dengan mencegah penumpukan plak pada gigi. Menyikat gigi dengan benar dan terampil pada waktu yang tepat merupakan hal yang positif dalam sikap seseorang. Berdasarkan hasil penelitian terhadap 100 penderita diabetes mellitus puskesmas II Denpasar Utara, responden yang berperilaku perlu bimbingan menyikat gigi sebesar 42 orang atau $86 \%$. Penelitian sesuai dengan hasil riskesdas 2013 yang menyatakan bahwa hanya $7 \%$ masyarakat menyikat gigi dengan benar walau hasil survey menemukan sudah 90\% masyarakat Indonesia menyikat gigi setiap hari (7). Sesudah diberikan penyuluhan dengan metode ceramah dan pemberian booklet terhadap masingmasing 50 responden, nilai median pengetahun meningkat menjadi 9 pada kelompok yang diberi ceramah dan 8,54 pada kelompok yang diberi booklet. yang diikuti juga dengan peningkatan jumlah responden yang bersikap benar menjadi 17 responden atau $34 \%$ pada kelompok ceramah dan 29 responden atau $58 \%$ pada respondn yang diberi booklet.Menurut Herdiati dan Sasmita, (2012) salah satu pencegahan yang dilakukan adalah pencegahan Primer: yaitu suatu bentuk prosedur pencegahan sebelum gejala klinik dari suatu penyakit timbul dengan kata lain pencegahan sebelum terjadinya penyakit. Tindakan primer meliputi modifikasi kebiasaan seseorang, pendidikan kesehatan gigi, kebersihan mulut, diet dan konsumsi gula, perlindungan terhadap gigi. perlindungan terhadap gigi dapat dilakukan dengan cara penggunaan fluor dan aplikasi bahan sealant, melakukan pembersihan karang gigi secara berkala ${ }^{(8)}$. Berdasarkan hasil analisis menunjukkan bahwa terdapat pengaruh signifikan terhadap perilaku pemeliharaan kebersihan gigi dan mulut sebelum dan sesudah diberikan penyuluhan dengan metode media booklet diperoleh nilai $(\mathrm{p}=0,00)$ yakni $(\mathrm{p}<0,05)$. Proses dari belajar yang diberikan melalui program penyuluhan dan pemberian booklet dapat dimengerti dan dipraktekkan dalam keseharian responden, sehingga dengan penyuluhan peragaan memiliki dampak yang efektif dalam menunjang peningkatan kebersihan gigi dan mulut pada responden di Puskesmas II Denpasar Utara. Metode pembagian booklet setelah diberikan ceramah yang berisi pesan-pesan cara melakukan suatu tindakan atau prosedur, dengan diberikan penerangan secara lisan, 
tertulis, gambar, dan ilustrasi ${ }^{(9)}$. Mahnoor, dkk. (2015) menyatakan bahwa metode ceramah yang ditambah dengan media booklet lebih efektif dalam meningkatkan kesehatan gigi dan mulutnya termasuk gingiva dibandingkan dengan hanya menggunakan ceramah saja (10). Media booklet dapat membantu responden mengingat bagian-bagian gigi yang biasa disikat sewaktu dirumah sehingga responden lebih mengerti ketika ditunjukkan bagian-bagian gigi yang harus disikat dengan cara melihat kembali petunjuk pada booklet. Perubahan perilaku akan cepat terjadi karena responden telah sering mempraktekkan penyikatan gigi secara baik dan benar dirumah. Didukung dengan kepedulian responden terhadap pemeliharaan kesehatan gigi dan mulut juga sudah cukup baik, sehingga tingkat kebersihan gigi dan mulut tetap terjaga.

Perilaku yang didasari oleh pengetahuan akan lebih langgeng daripada perilaku yang tidak didasari oleh pengetahuan. Perubahan atau adopsi perilaku baru adalah suatu proses yang kompleks dan memerlukan waktu yang lama ${ }^{(11)}$. Berdasarkan penelitian, langkah perubahan perilaku terdiri atas 3 tahap. Untuk melalui ketiga tahapan tersebut, dibutuhkan waktu minimal 21 hari. Pada 7 hari pertama adalah tahapan menanamkan pengetahuan untuk mempengaruhi pola pikir. Tujuh hari kedua adalah tahapan internalisasi untuk menjadikan suatu perilaku yang telah diketahui sebagai pola sikap atau kebiasaan, dan 7 hari terakhir merupakan tahapan untuk mengubah pola sikap menjadi budaya baru ${ }^{(7)}$. Hasil penelitian juga membuktikan bahwa terdapat pengaruh secara bermakna antara sebelum dan sesudah diberikan media booklet pada responden yaitu nilai $\mathrm{p}=0,00$ $(\mathrm{p}<0,05)$. Hal ini menunjukkan bahwa responden telah menyikat gigi dengan benar setelah diberikan booklet. Sebelum diberikan penyuluhan dan booklet responden selalu menyikat gigi setiap hari tetapi cara atau teknik menyikat gigi masih memerlukan bimbingan. Perilaku menyikat gigi dapat mengurangi terjadinya penyakit gigi dan mulut seperti karies dan jaringan periodontal. Faktor lain yang mempengaruhi perilaku responden adalah status penyuluh atau pemberi informasi, jika informasi atau penyuluhan dilakukan oleh petugas kesehatan gigi dapat memotivasi dan intruksi sehingga pasien bisa lebih peduli pada kesehatan gigi dan mulut (9). Dorongan motivasi yang diberikan dokter gigi pada penderita menyebabkan terjadinya penurunan jumlah plak pada pasien yang menjalani perawatan ${ }^{(9)}$. 
Berdasarkan hasil penelitian terbukti bahwa sesudah diberikan penyuluhan dan booklet oleh peneliti yang juga sebagai tenaga kesehatan gigi terdapat pengaruh yang kuat antara perubahan perilaku yakni $\mathrm{p}=0,00 \quad(<0,005)$. Hal ini menunjukkan bahwa sesudah diberikan penyuluhan dan pembagian boklet pengetahuan, sikap, dan praktek/tindakan sebagai bagian dari perilaku mengenai pemeliharaan kebersihan gigi dan mulut berupa menyikat gigi secara benar sudah diadopsi oleh responden di Puskesmas II Denpasar Utara. Model promosi kesehatan gigi dan mulut dipengaruhi oleh pengetahuan, emosional, lingkungan, dan perilaku. Dalam dunia kedokteran gigi, pembelajaran dihubungkan dengan ranah pengetahuan, sikap, dan psikomotor. Pembelajaran yang sistematis bervariasi tergantung individu atau sasaran populasi. Sangat penting untuk mempertahankan kontak antara penyuluh dengan individu yang diberikan penyuluhan untuk membentuk kerangka saling percaya, memastikan proses komunikasi yang berhasil. Perubahan perilaku merupakan aktivitas kompleks yang memerlukan usaha, praktek dan membangun hubungan antar tiap individu (12). Salah satu upaya yang dapat dilakukan untuk mencegah kelaianan periodontal pada pasien diabetes melitus adalah dengan meningkatkan pengetahuan tentang cara menyikat gigi yang benar. Pengetahuan atau kognitif merupakan domain yang sangat penting dalam merubah sikap dan memberikan tindakan seseorang ${ }^{(13)}$. Sikap sebagai sekumpulan respon yang konsisten terhadap obyek sosial. Sikap merupakan predisposisi perilaku, atau reaksi tertutup. Sikap merupakan komponen penting dalam jiwa manusia yang akan mempengaruhi perilaku seseorang (11). Perilaku menyikat gigi merupakan salah satu perilaku kebersihan dan kesehatan yang sangat penting dan efektif untuk pemeliharaan kesehatan gigi dan mulut dengan mencegah terjadinya plak pada gigi ${ }^{(14)}$.

\section{Simpulan dan Saran}

Penggunaan media booklet berpengaruh terhadap peningkatan pengetahuan, Sikap dan perilaku pasien diabetes mellitus dalam upaya pencegahan kelainan periodontal. Disarankan kepada pemegang program penyakit tidak menular dan program kesehatan gigi dan mulut selalu bekerjasama untuk memberikan penyuluhan secara berkala kepada pasien Diabetes melitus untuk menegaskan bahwa menyikat gigi yang benar itu sangat penting dalam menjaga kesehatan secara umum. Kepada responden suapaya 
tetap menjaga kebersihan gigi dan mulutnya dengan cara menyikat gigi yang benar dan waktu yang benar yaitu pagi setelah makan dan malam sebelum tidur.

\section{DAFTAR PUSTAKA}

1. Askandar.T. (2007). Diabetes Mellitus. Gramedia Pustaka Utama, Jakarta

2. Bustan.M.N. (2007). Epidimiologi Penyakit Tidak Menular. Rineka Cipta, Jakarta: 100-118.

3. Lely S \& Indirawati T. (2004). Pengaruh Kadar Glukosa Darah Yang Terkontrol Terhadap Penurunan Derajat Kegoyangan Gigi Penderita Diabetes Mellitus Di RS Persahabatan Jakarta. Media Litbang Kesehatan Vol.XIV No.3.

4. Berliana Sari, Idham Halid, Pahrur Razi.(2017). Hububungan Pengetahuan Status Kebersihan Gigi dan Mulut pada Penderita Diabetes Mellitus di Puskesmas Rawang Jambi, Jurnal Kesehatan Gigi Vol. 4 No.1 Juni 2017

5. Arikunto, S., 2000, Asuhan Keperawatan Keluarga Aplikasi dalam Praktek. Jakarta : Depkes RI.

6. Martono N, 2010, Statististik Sosial, Teori dan Aplikasi Program SPSS, Yogyakarta, Gava Media.

7. Kementerian Pendidikan dan Kebudayaan, 2013. Model Penilaian Hasil Belajar Peserta Didik. Direktorat Jenderal Pendidikan Menengah. Direktorat Pembinaan SMA.
8. Hidriyana, Ayu. (2011). Hubungan Antara Periodontitis Dengan Diabetes Mellitus Tipe 2 Ditinjau Dari Aspek Kebutuhan Perawatan Periodontal. Sumatra Utara: PS. Kedokteran gigi Universitas Sumatera Utara Medan.

9. Galag, C.J.R., dkk., 2015. Status Kebersihan Mulut pada Pengguna Alat Ortodontik Cekat Berdasarkan Oral Hygiene Index Simplified di Sekolah Menengah Atas Negeri 1 Manado, Jurnal e-GiGi (eG), 3(2): 298-301.

10. Mahnoor, M., dkk., 2015. Effect of two different oral hygiene motivation methods on gingival health of patients with fixed orthodontic appliance. POJ 7(1): 17-24.

11. Notoatmodjo, S, 2007. Promosi Kesehatan dan Ilmu Perilaku. Jakarta, Rineka Cipta.

12. Bardal, P.A.P, Olympio, K.P.K, Bastos, J.P.M., Henriques, J.F.C., Buzalaf, M.A.R., 2011. Education and motivation in oral health preventing disease and promoting health in patients undergoing orthodontic treatment. Dental Press J Orthod, 16 (3): 95-102.

13. Notoatmodjo, S, 2010. Ilmu Perilaku Kesehatan. Jakarta, Rineka Cipta.

14. Kementerian Kesehatan RI, 2012. Pedoman Usaha Kesehatan Gigi Sekolah (UKGS). Jakarta, Direktorat Jenderal Bina Upaya Kesehatan, Kementerian Kesehatan RI. 
